\title{
Mitochondrial reactive oxygen species (ROS) as signaling molecules of intracellular pathways triggered by the cardiac renin-angiotensin II-aldosterone system (RAAS)
}

\author{
V. C. De Giusti, C. I. Caldiz, I. L. Ennis, N. G. Pérez, H. E. Cingolani and E. A. Aiello*
}

Facultad de Ciencias Médicas, Centro de Investigaciones Cardiovasculares, UNLP-CONICET, La Plata, Argentina

\section{Edited by:}

Sabzali Javadov, University of Puerto Rico School of Medicine, Puerto Rico

Reviewed by:

Amadou K. Camara, Medical College of Wisconsin, USA

Elena N. Dedkova, Rush University

Medical Center, USA

John Hollander, West Virginia

University School of Medicine, USA

*Correspondence:

E. A. Aiello, Facultad de Ciencias

Médicas, Centro de Investigaciones Cardiovasculares, UNLP-CONICET

Calle 60 y 120, La Plata 1900,

Argentina

e-mail: aaiello@med.unlp.edu.ar
Mitochondria represent major sources of basal reactive oxygen species (ROS) production of the cardiomyocyte. The role of ROS as signaling molecules that mediate different intracellular pathways has gained increasing interest among physiologists in the last years. In our lab, we have been studying the participation of mitochondrial ROS in the intracellular pathways triggered by the renin-angiotensin II-aldosterone system (RAAS) in the myocardium during the past few years. We have demonstrated that acute activation of cardiac RAAS induces mitochondrial ATP-dependent potassium channel (mitoK $\mathrm{K}_{\text {ATP }}$ ) opening with the consequent enhanced production of mitochondrial ROS. These oxidant molecules, in turn, activate membrane transporters, as sodium/hydrogen exchanger (NHE-1) and sodium/bicarbonate cotransporter (NBC) via the stimulation of the ROS-sensitive MAPK cascade. The stimulation of such effectors leads to an increase in cardiac contractility. In addition, it is feasible to suggest that a sustained enhanced production of mitochondrial ROS induced by chronic cardiac RAAS, and hence, chronic NHE-1 and NBC stimulation, would also result in the development of cardiac hypertrophy.

Keywords: cardiac myocyte, second messenger systems, sodium-hydrogen antiporter, sodium-bicarbonate symporters, reactive oxygen species

\section{INTRODUCTION}

The renin-angiotensin-aldosterone-system (RAAS) represents one of the main endocrine systems that regulate cardiac physiology. At present, it is well recognized that angiotensin II (Ang II) is produced and secreted locally in several tissues, including the heart (Husain et al., 1994). Sadoshima's group has shown that the hormone is secreted from intracellular vacuoles in response to myocyte stretching for the first time. This Ang II exerts autocrine and paracrine effects, leading to cardiac hypertrophy (Sadoshima et al., 1993; Sadoshima and Izumo, 1996). Cingolani's group conducted an in depth study of this autocrine pathway as a physiological mechanism responsible for the slow force response (SFR) to myocardial stretch (Cingolani et al., 2001, 2003) and showed the similarities of both the physiological and pathological pathways (Cingolani et al., 2008). The critical role played by the cardiac $\mathrm{Na}^{+} / \mathrm{H}^{+}$exchanger (NHE-1) activation in both physiological and pathological responses was demonstrated not only pharmacologically with NHE-1 inhibitors (Cingolani et al., 2011) but also by specific NHE-1 silencing following direct intramyocardial injection of small interfering RNA into rat left ventricular wall (Morgan et al., 2011; Cingolani et al., 2013). The precise mechanism to explain pathological responses is unclear and warrants further investigation. However, it is possible that the time of exposure to the stimulus and the amount of ROS produced could be important in determining the physiological or pathological pathways. Increasing time and amount of ROS exposure could exert a differential impact in calcium handling, an initial acute response leading to inotropic effects followed by a sustained response that could involve calcium-activated targets that participate in cardiac hypertrophy or heart failure, like calcineurin, or $\mathrm{Ca}^{2+}$-calmodulin-dependent kinase type II (CaMKII).

Although still somewhat controversial (Silvestre et al., 1998, 1999; Takeda et al., 2000; Gomez-Sanchez et al., 2004; Chai and Danser, 2006), it has been suggested that aldosterone synthase exists in the myocyte (Silvestre et al., 1998, 1999; Takeda et al., 2000), supporting the presence of a local RAAS (Varagic and Frohlich, 2002). Furthermore, the link between Ang II or its $\mathrm{AT}_{1}$ receptor, and the mineralocorticoid receptor $(\mathrm{MR})$ is an accepted fact (Lemarie et al., 2008; Grossmann and Gekle, 2009). Consistently, it has also been described that some physiological cardiac effects of Ang II, as the SFR, can be prevented in the presence of MR blockers (Caldiz et al., 2011).

Although the idea that mitochondria are the main sources of basal reactive oxygen species (ROS) in other mammalian cells has been recently challenged, (Brown and Borutaite, 2012) their role as a very important source of ROS in the heart has been widely accepted. Mitochondrial superoxide anion $\left(\mathrm{O}_{2}{ }^{-}\right)$ and its product, hydrogen peroxide $\left(\mathrm{H}_{2} \mathrm{O}_{2}\right)$, were demonstrated to be important molecules implicated in several cardiac functions usually acting as second signal molecules of RAAS (Kimura et al., 2005a,b; Caldiz et al., 2007, 2011; De Giusti et al., 2008, 2009).

In this review, we will briefly summarize the current knowledge about the involvement of mitochondrial ROS as mediators of the signaling pathways triggered by RAAS in cardiac 
myocytes without stressing out if they participate in acute or chronic signals. We will discuss the participation of the different components of RAAS in ROS production and in cardiac signaling leading to physiological and pathological responses. Particularly, we will remark the implication of the ion transporters (NHE-1 and NBC) in sodium and calcium overload and its relation with ROS signaling.

\section{ANGIOTENSIN II, ENDOTHELIN-1, ALDOSTERONE AND EPIDERMAL GROWTH FACTOR: INDEPENDENT SIGNALS OR DIFFERENT COMPONENTS OF THE SAME CARDIAC SYSTEM?}

Ang II is involved in the regulation of almost all cardiac functions. At present, it is well known that Ang II stimulates membrane ions transporters as NHE-1 (Fliegel and Karmazyn, 2004; Cingolani et al., 2005) and $\mathrm{Na}^{+} / \mathrm{HCO}_{3}{ }^{-}$cotransporter (NBC) (Baetz et al., 2002; De Giusti et al., 2009; Aiello and De Giusti, 2012). These regulations are crucial for the correct electrical and mechanical cardiac functions. On the other hand, it is important to keep in mind that when RAAS is chronically active it is responsible for several cardiac diseases, for example, hypertrophy, heart failure and electrical disturbances (Domenighetti et al., 2007; Fischer et al., 2007; Mehta and Griendling, 2007; Palomeque et al., 2009; Li et al., 2013).

The mechanism of how the activation of NHE-1 or NBC regulates cardiac contractility seems to involve the increase in intracellular $\mathrm{Na}^{+}$concentration $\left(\left[\mathrm{Na}^{+}\right]_{\mathrm{i}}\right)$ (Vaughan-Jones et al., 2006) due to the activation of these transporters and the subsequent increase in intracellular calcium concentration $\left(\left[\mathrm{Ca}^{2+}\right]_{\mathrm{i}}\right)$ due to the activation of the reverse mode of the $\mathrm{Na}^{+} / \mathrm{Ca}^{2+}$ exchanger (NCX) (Perez et al., 2001; Rothstein et al., 2002; Bril, 2003; Morgan et al., 2011). Interestingly, the same pathway is proposed to explain the development of cardiac hypertrophy (Ennis et al., 2007; Cingolani et al., 2008).

In addition, endothelin-1 (ET-1) and aldosterone (Ald) are key modulators of cardiac physiology per se. We have shown that ET-1 activates the NHE-1 (Aiello et al., 2005; De Giusti et al., 2008) leading to a positive inotropic effect (Szokodi et al., 2008). Moreover, Ald has been shown to activate NHE-1, (De Giusti et al., 2011) increase NHE-1 expression (Karmazyn et al., 2003) and induce left ventricular hypertrophy independently from its classical effects on regulation of renal $\mathrm{Na}^{+}$excretion and blood pressure (Qin et al., 2003; Yoshida et al., 2005; Diez, 2008). Classically, Ald enters the cells and binds to the MR located mainly in the cytosol. This binding translocates the MR to the nucleus, where it acts as a ligand-induced transcription factor. However, evidence has been presented that activated MR can elicit additional non-classical effects, which do not require transcription or translation of genes (Ebata et al., 1999; Mihailidou et al., 2004; Chai et al., 2005; Grossmann and Gekle, 2009). In addition, several of these rapid nongenomic effects of Ald involves the transactivation of the epidermal growth factor receptor (EGFR) (Grossmann and Gekle, 2007; Grossmann et al., 2007), which can, in turn, stimulate the NHE-1 (De Giusti et al., 2011). Moreover, it was reported that at least a small fraction of the classic MR is located in the cell plasma membrane where it is co-localized with the EGFR, inducing the transactivation of the latter (Grossmann et al., 2010).

More recently, it was demonstrated that certain non-genomic effects of Ald in vascular smooth muscle were due to simultaneous activation of MR and a surface membrane G protein-coupled receptor, the GPR30 (Gros et al., 2011, 2013). In agreement, growing evidence is appearing which demonstrate that GPR30 could be another Ald receptor involved in the rapid effects of the hormone in the cardiovascular system (Gros et al., 2011; Meyer et al., 2011).

At present, it is accepted that many effects initially believed to be mediated by Ang II, as the positive inotropic effect (PIE), and the increase in the SFR after myocardial stretching, are in fact attributable to the action of ET-1, which is released by Ang II (Perez et al., 2003; Cingolani et al., 2006, 2008; Villa-Abrille et al., 2006). Moreover, Ald appears to mediate some Ang II effects that participate in the same pathway of Ang II and ET-1 (Figure 1) (Xiao et al., 2004; Lemarie et al., 2008; Caldiz et al., 2011). Recently, it has been demonstrated that EGF is also implicated in cardiac physiology (De Giusti et al., 2011), and it has been described that the transactivation of the EGF receptor (EGFR) is involved in some RAAS effects (Shah and Catt, 2003; Zhai et al., 2006; De Giusti et al., 2011). We have suggested that all these extracellular and intracellular stimuli are pieces of the same signaling pathway (Figure 1). In this scenario, the activation of the MR takes place downstream from the Ang II/ET-1 receptors and upstream of the EGFR. The activation of EGFR triggers the intracellular ROS production, which leads to the stimulation of different kinases that finally activate the NHE-1 (Caldiz et al., 2011).

Interestingly, almost all the effects of these hormones involve ROS-mediated pathways (Zhang et al., 2001; Caldiz et al., 2007, 2011; Bartosz, 2009). In this regard, it is accepted that Ang II, (Giordano, 2005; Kimura et al., 2005b; De Giusti et al., 2009), ET-1 (De Giusti et al., 2008; Kubin et al., 2011), Ald (Hayashi et al., 2008; Caldiz et al., 2011) and EGF (De Giusti et al., 2011) can activate NADPH oxidase (NOX), which then, as further explained below, can stimulate mitochondrial ROS production and mediate the effects of such hormones (Figure 1). Therefore, it seems clear that RAAS effects are in close relationship with ROS generation, and in order to be able to modulate RAAS signaling, we should investigate the regulation of ROS production in detail.

\section{MAJOR SOURCES OF ROS: NOX, MITOCHONDRIA AND THEIR CROSS-TALK}

ROS have been considered deleterious agents for a long time. However, in the last years, evidence has emerged supporting their role as second messengers (D'autreaux and Toledano, 2007). Under physiological conditions, the production of ROS is highly restricted to specific subcellular sites. The major sources of ROS in the cardiomyocytes are NOX (Bedard and Krause, 2007) and the I, II and III complexes of the mitochondrial respiratory chain (Camara et al., 2010; Dedkova et al., 2013; Drose, 2013; Li et al., 2013; Wojtovich et al., 2013). In this regard, complex II is emerging as the major modulator of mitochondrial 


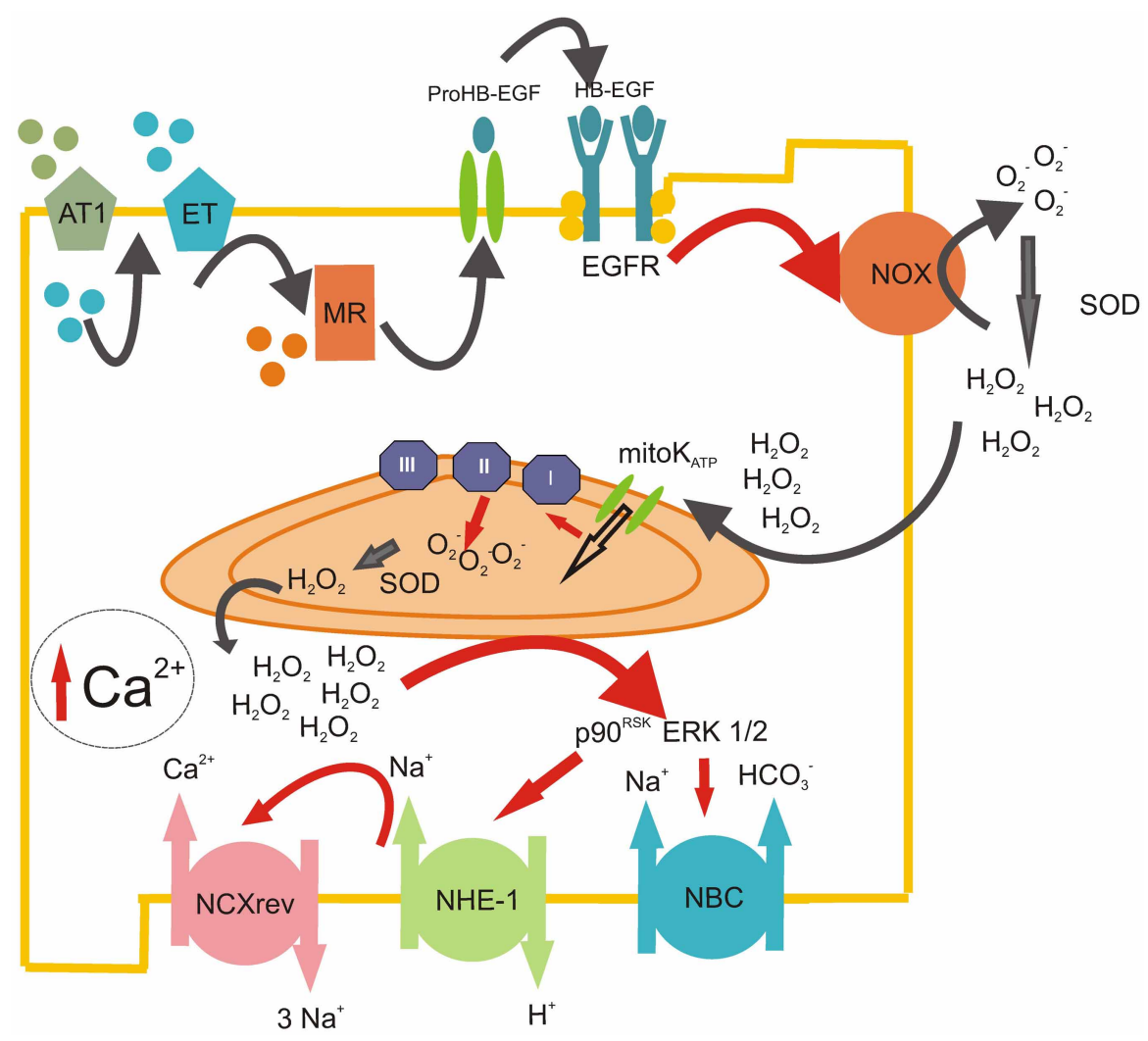

FIGURE 1 | ROS-induced ROS-release mechanism triggered by RAAS. Scheme representing the sequential steps involved in the production of mitochondrial ROS after the initial Ang II stimulation. Ang II acting on $\mathrm{AT}_{1}$ receptors induces the release of intracellular ET-1, which, in turn, acts in an autocrine manner on $\mathrm{ET}_{\mathrm{A}}$ receptors. This autocrine action leads to the activation of the mineralocorticoid receptor (MR), which induces the transactivation of the EGFR, possibly via the release of membrane heparin-bound EGF (HB-EGF). The stimulation of the EGFR leads to the activation of the NADPH oxidase (NOX), which produces superoxide anion $\left(\mathrm{O}_{2}{ }^{-}\right)$and quickly dismutate by superoxide dismutase (SOD) to hydrogen peroxide $\left(\mathrm{H}_{2} \mathrm{O}_{2}\right)$. This permanent and stable oxidant molecule produces the opening of mitochondrial ATP-dependant potassium channels (mitoK ATP $_{\text {) with }}$ the subsequent enhanced production of mitochondrial $\mathrm{O}_{2}-$ by the electron transport chain (mainly by complex II). These mitochondrial ROS are released to the cytosol (ROS-induced ROS-release mechanism), where they stimulate redox sensitive MAPkinases ERK $1 / 2$ and $p 90^{\mathrm{RSK}}$, which, in turn, activate $\mathrm{NHE}-1$ and $\mathrm{NBC}, \mathrm{pH}$ regulation transporters that induce the increase in intracellular $\mathrm{Na}^{+}$. Finally, this cytosolic $\mathrm{Na}^{+}$increase favors the operation of the reverse mode of $\mathrm{NCX}$, promoting the influx of $\mathrm{Ca}^{2+}$ into the cell. The enhancement of intracellular $\mathrm{Ca}^{2+}$ in the cardiomyocyte could lead to a positive inotropic effect in the short term and/or the development of cardiac hypertrophy in a time-prolonged scenario.
ROS production (Drose, 2013). Moreover, it was proposed that complex II can adopt different roles as a producer or modulator of mitochondrial ROS, depending on the substrate supply and the activities of the other respiratory chain complexes (Drose, 2013). The primary function of complex II is to maintain the reduced state of mitochondrial chain complexes (Wojtovich et al., 2013). Importantly, it was demonstrated that complex II, instead of complex I or III, is the major source of ROS during heart failure (Dedkova et al., 2013). On the other hand, it has been proposed that the production of "deleterious ROS" during reperfusion can be related to complex I, while the generation of "signaling ROS" during preconditioning occurs at complex II (Drose, 2013). Although the precise mechanism is not clear yet, the modulation of complex II seems to be cardioprotective during ischemic preconditioning (Wojtovich et al., 2013). These data, however, do not support previous results which suggested that the production of ROS induced after mitoK $K_{\text {ATP }}$ opening is accounted by complex I (Andrukhiv et al., 2006), and that ischemic preconditioning is mediated by ROS generated after the activation of these channels (Oldenburg et al., 2004).

At present it is accepted that NOX produce extracellular $\mathrm{O}_{2}{ }^{-}$, which dismutate to $\mathrm{H}_{2} \mathrm{O}_{2}$. Although it has been generally assumed that $\mathrm{H}_{2} \mathrm{O}_{2}$ diffuses back into the cell across the plasma membrane, recent evidence suggests that it might preferentially enter the cell through specific aquaporin channels (Bienert et al., 2007; Miller et al., 2010), providing a potential mechanism through which ROS signaling could be regulated. It is also accepted that matrix $\mathrm{H}_{2} \mathrm{O}_{2}$ permeates through the mitochondrial inner membrane after being produced by the action of $\mathrm{Mn}-\mathrm{SOD}$, which dismutates mitochondrial $\mathrm{O}_{2}^{-}$. However, it is important to note that $\mathrm{O}_{2}{ }^{-}$also permeates mitochondrial membrane through anion channels (Bedard and Krause, 2007) and hence could potentially act as a signaling molecule. The SFR, which represents an acute and physiological response triggered by RAAS activation, was reported to be due to $\mathrm{H}_{2} \mathrm{O}_{2}$ signaling 
(Caldiz et al., 2007). Moreover, experiments by Sabri et al. (1998) and Rothstein et al. (2002) indicated that $\mathrm{H}_{2} \mathrm{O}_{2}$ is the intracellular signal leading to the activation of kinases that phosphorylate the NHE-1. On the other hand, $\mathrm{O}_{2}{ }^{-}-$not $\mathrm{H}_{2} \mathrm{O}_{2}$ - was reported to be the signaling molecule in the ET-1-induced stimulation of cardiac L-type calcium channels (Zeng et al., 2008). Nevertheless, if mitochondrial $\mathrm{H}_{2} \mathrm{O}_{2}$ or $\mathrm{O}_{2}{ }^{-}$could cause different responses to RAAS activation, i.e., acute versus chronic, it would be an interesting topic that deserves future investigation.

NOX and mitochondria are not totally independent sources of ROS, since recent evidence demonstrate the existence of a substantial interplay between both sources, such as activation of one leading to the activation of the other (Dikalov, 2011). In 2000, Zorov et al. (2000) published the first study describing the phenomenon called "ROS-induced ROS-release" by which a small amount of ROS triggers greater ROS production from the mitochondria. Five years later, Dr. Kimura's group proposed the Ang II-induced NOX stimulation as the generator of the small amount of ROS triggering mitochondrial ROS production (Kimura et al., 2005a) (Figure 1). It is important to note that this "ROS-induced ROS-release" mechanism is implicated in Ang II-mediated preconditioning.

The main link between both sources of ROS seems to be the mitochondrial ATP-dependent potassium channel ( mitoK $_{\text {ATP }}$ ). It was demonstrated that the opening of these channels is crucial to stimulate ROS production by the respiratory chain. Three phenomena were proposed to activate the mitochondrial respiratory chain and produce ROS: moderate matrix swelling, matrix alkalinization and inner membrane depolarization (Pain et al., 2000; Andrukhiv et al., 2006). A still unresolved issue is how the mitoK $K_{\text {ATP }}$ are opened. On the one hand, it has been reported that $\mathrm{O}_{2}^{-}$can directly stimulate the mitoK ${ }_{\text {ATP }}$, (Zhang et al., 2001, 2007) on the other hand, there is enough evidence that demonstrate the involvement of PKC as an activator of mitoK $\mathrm{KTP}_{\text {(Sato }}$ et al., 1998; Costa et al., 2006; Costa and Garlid, 2008). In addition, other studies have proposed that the cardioprotective effect of $\mathrm{G}_{\mathrm{i}}$-coupled receptor agonists are due to EGFR transactivation and subsequent stimulation of the PI3K/Akt pathway, which lead to a PKG-mediated opening of $\mathrm{mK}_{\mathrm{ATP}}$ channels and increased $\mathrm{O}_{2}{ }^{-}$production (Krieg et al., 2002, 2003, 2004). These authors proposed that PI3K/Akt increase nitric oxide levels, which, in turn, stimulates the guanylate cyclase, augmenting cGMP content and activating $\mathrm{PKG}$, inducing the opening of mitoK $\mathrm{KTP}_{\mathrm{AT}}$ channels (Krieg et al., 2004; Oldenburg et al., 2004).

Interestingly, it seems that not only NOX-derived ROS trigger mitochondrial ROS production, but also a small amount of mitochondrial ROS released to the cytosol could potentially further activate ROS-induced ROS-release in neighboring mitochondria (Costa and Garlid, 2008). In addition, mitochondrial ROS can stimulate NOX directly or mediated by PKC activation (Doughan et al., 2008; Wenzel et al., 2008; Camara et al., 2010; Dikalov, 2011). These different signaling regulations create a truly crosstalk between the major sources of ROS (Daiber, 2010). This issue is important because it converts the mitochondrion to a ROSamplifier. Myocytes spend little energy to start the intracellular signaling and then the cycle helps to potentiate ROS-production (Figure 2).

\section{THE MITOCHONDRIAL ROS ARE THE MEDIATORS OF RAAS- INDUCED NHE-1 AND NBC REGULATION, OR IS IT THE OPPOSITE?}

ROS-mediated activation of NHE-1 (Sabri et al., 1998; Snabaitis et al., 2002; Caldiz et al., 2007, 2011; De Giusti et al., 2008) and NBC (De Giusti et al., 2009; Aiello and De Giusti, 2012) has been reported to be due to redox sensitive kinase-mediated phosphorylation. In this regard, there is enough evidence supporting the notion that ROS favors the activation of ERK $1 / 2$ and $\mathrm{p} 90^{\mathrm{RSK}}$ in neonatal and adult cardiomyocytes (Sabri et al., 1998; Rothstein et al., 2002).

As described above, the components of RAAS are well known activators of ROS production (Hanna et al., 2002; Seshiah et al., 2002; Kimura et al., 2005b; Doughan et al., 2008). Moreover, in our lab, we have investigated the pathway by which myocardial stretch sequentially stimulates ROS production, activates ERK 1/2 and $\mathrm{p} 90^{\mathrm{RSK}}$ and finally leads to the stimulation of NHE-1 (Caldiz et al., 2007, 2011; Villa-Abrille et al., 2010). We demonstrated that NHE-1 stimulation is responsible for the SFR in the acute phase. Thus, we proposed that NHE-1 stimulation is potentially responsible, in a more prolonged term, for chronic and pathological responses, such as the development of cardiac hypertrophy (Cingolani et al., 2008).

As Figure 1 shows, RAAS signaling leads to an increase in ROS production and subsequent activation of ERK $1 / 2$ and $\mathrm{p} 90^{\mathrm{RSK}}$ kinases, which stimulate both transporters, NHE-1 and NBC. The stimulation of these transporters might lead to an increase in $\left[\mathrm{Na}^{+}\right]_{\mathrm{i}}$ (Vaughan-Jones et al., 2006), which is known to induce the operation of the reverse mode of NCX, leading to an increase in $\left[\mathrm{Ca}^{2+}\right]_{\mathrm{i}}$ and a positive inotropic effect. Mitochondrial $\mathrm{Ca}^{2+}$ $\left(\mathrm{mCa}^{2+}\right)$ uptake through the calcium uniporter $(\mathrm{CaU})$ is in part dependent on the $\mathrm{Ca}^{2+}$ gradient between the cytosol and the mitochondrial matrix (Camara et al., 2010). Thus, it seems evident that the cytosolic $\mathrm{Ca}^{2+}$ increase, following the activation of NHE-1 and NBC, may lead to an increase in $\mathrm{mCa}^{2+}$. Mitochondrial $\mathrm{Ca}^{2+}$ loading regulates cellular respiration and mediates cell death (Camara et al., 2010). Calcium, through the activation of the CaMKII, was described as one of the main activators of NOX (Nishio et al., 2012) and mitochondrial ROS production (Song et al., 2011), creating a positive feed-back (feedback 3, Figure 2) by which the ROS pathways acquire a central role in cell physiology (Trebak et al., 2010; Gul et al., 2012).

It has been described that the NHE-1 blockers attenuate the $\mathrm{mCa}^{2+}$ overload, ROS production and MPTP opening induced by ouabain (Toda et al., 2007). These authors proposed two possible mechanisms: (a) the NHE-1 inhibition prevents the increase in $\left[\mathrm{Na}^{+}\right]_{i}$ and subsequent $\left[\mathrm{Ca}^{2+}\right]_{i}$, which reduces the driving force for $\mathrm{mCa}^{2+}$ uptake, and (b) NHE-1 inhibition might indirectly activate the mitoK $K_{\mathrm{ATP}}$ channel (the protection induced by NHE-1 blockers is prevented with the mitoK $\mathrm{K}_{\mathrm{ATP}}$ blocker 5 HD). In addition, it has been demonstrated that NHE-1 inhibition prevents MPTP opening during the first minutes after reperfusion, leading to an improvement of mitochondrial function as well as an attenuation of pro-apoptotic factors. In this work, the authors discussed several possibilities for the NHE1-inhibition-induced protection, being the most important the attenuation of $\left[\mathrm{Ca}^{2+}\right]_{\mathrm{i}}$ overload and the delay of $\mathrm{pH}_{\mathrm{i}}$ recovery 


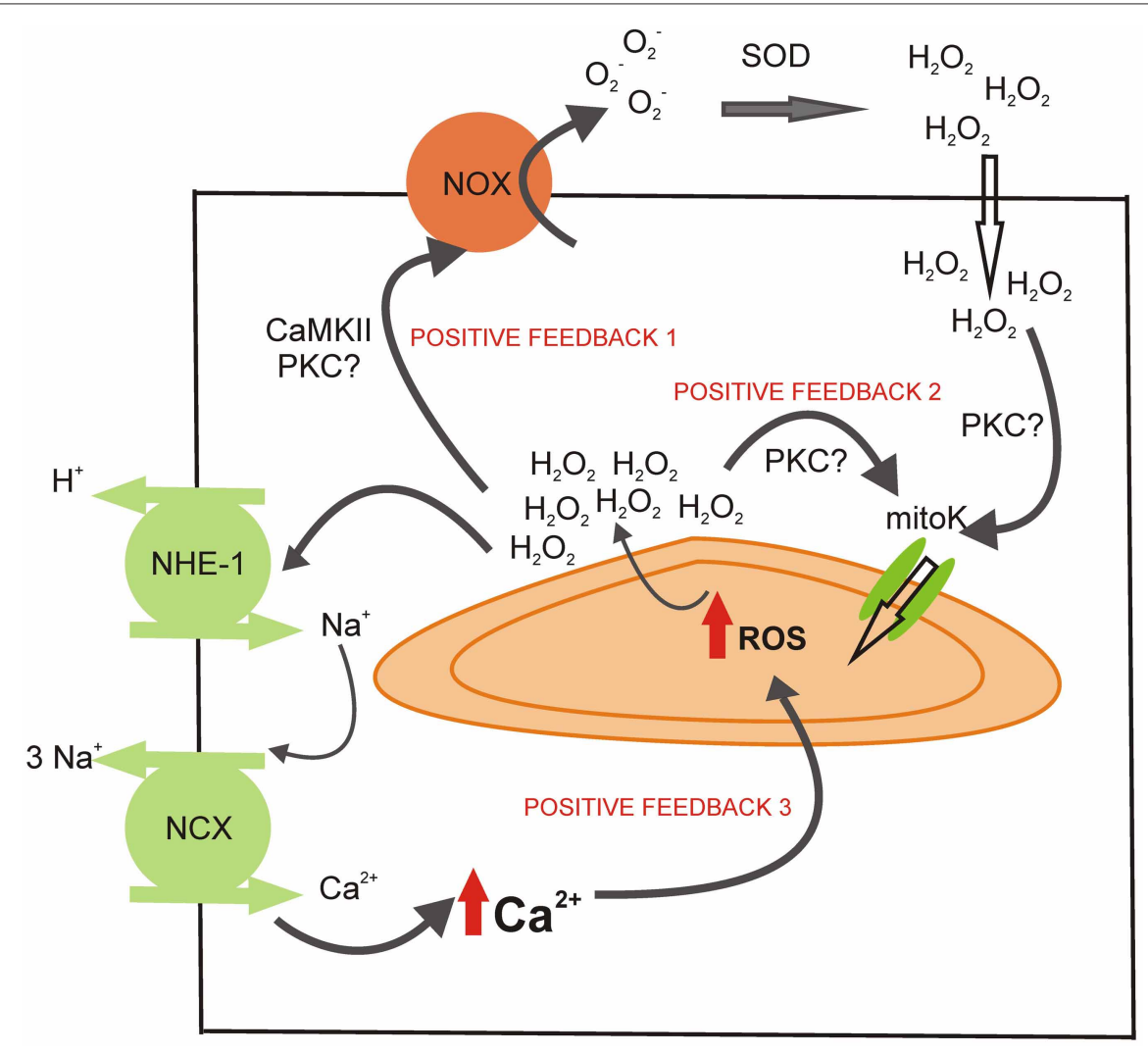

FIGURE 2 | Potential sites of positive feedback mechanisms involved in the mitochondrial ROS production during the activation of RAAS. The $\mathrm{H}_{2} \mathrm{O}_{2}$ released by the mitochondria during the ROS-induced ROS-release mechanism could activate NOX (possibly via CaMKII or PKC activation), cycling the mitochondrial ROS production (positive feedback 1). The mitochondrial ROS could also help to maintain the opening of mitoK $K_{\text {ATP }}$ (positive feedback 2), perhaps through the activation of PKC. Finally, the intracellular $\mathrm{Ca}^{2+}$ augmentation after NHE- 1 and $\mathrm{NCX}$ reverse mode stimulation could induce mitochondrial $\mathrm{Ca}^{2+}$ load and further $\mathrm{ROS}$ production (positive feedback 3). during reperfusion (Javadov et al., 2008). Moreover, Garciarena et al. (2008) working on isolated mitochondria, showed that the NHE-1 inhibitors modulate mitochondrial ROS production via a direct mitochondrial action. However, the site of action has not been elucidated. Nevertheless, it is important to point out again that the careful regulation of ROS production, which involves the modulation of calcium handling, represents a crucial process in myocardial intracellular signaling (Figure 2).

\section{MITOCHONDRIAL ROS AND CARDIAC PATHOLOGY}

When the cells are exposed to the same stimuli for long periods of time, they begin to lose their equilibrium, and in this scenario ROS and $\mathrm{Ca}^{2+}$ might represent dangerous molecules, leading to arrhythmias and cardiac hypertrophy (Terentyev et al., 2008; Zhao et al., 2011; Maulik and Kumar, 2012). In this regard, high $\mathrm{mCa}^{2+}$ impairs ATP synthesis leading to a loss in ion homeostasis, opening of mPTP and matrix swelling. The irreversible mPTP opening is associated with release of cytochrome $\mathrm{C}$ and more ROS production, resulting in a harmful vicious cycle of further amplification of ROS production, $\mathrm{mCa}^{2+}$ overload and irreversible cell damage, which lead to cell death (Camara et al., 2010). On the other hand, several investigations have demonstrated that a low increase in matrix ROS is sufficient to trigger brief, stochastic openings of mPTP, perhaps through reversible thiol oxidation (Wang et al., 2008). Moreover, these transient brief openings of mPTP have been involved as a "physiological valve", alleviating $\mathrm{mCa}^{2+}$ overload and providing protection against cellular injury (Smaili and Russell, 1999; Kindler et al., 2003).

There are several evidences that involve the participation of ROS produced by NOX in different models of heart failure with RAAS activation (Sorescu and Griendling, 2002; Guo et al., 2006). Since NOX-produced ROS can be amplified by ROS generated by mitochondria during the ROS-induced-ROS release mechanism, this process could be also involved in the development of cardiac hypertrophy and the transition to heart failure. Indeed, it was reported that mice that overexpress catalase (antioxidant enzyme that degrades $\mathrm{H}_{2} \mathrm{O}_{2}$ ) targeted to mitochondria are resistant to cardiac hypertrophy, fibrosis and mitochondrial damage induced by Ang II as well as heart failure induced by overexpression of $\mathrm{G} \alpha \mathrm{q}$ (Dai et al., 2011). In addition, Ang II-induced mitochondrial ROS are implicated in the development of apoptosis (Choudhary et al., 2008). Thus, breaking the ROS vicious cycle within mitochondria by antioxidants specifically targeted to this organelle would be effective to attenuate both cardiac hypertrophy and failure.

It was recently demonstrated that Ang II binds to $\mathrm{AT}_{1}$ and $\mathrm{AT}_{2}$ receptors localized in the mitochondrial inner membrane 
$\left(\mathrm{mAT}_{1}\right.$ and $\left.\mathrm{mAT}_{2}\right)$ (Abadir et al., 2011). The authors of this study proposed an interesting model, where they associated the subtype of Ang II receptor and the type of ROS generated by mitochondria. In young animals, the activation of $\mathrm{mAT}_{2}$ induced protective mitochondrial $\mathrm{NO}$ generation. However, this protection disappeared with aging, possibly, due to harmful ROS producing an increased expression of $\mathrm{mAT}_{1}$. A similar speculation of $\mathrm{mAT}_{1}$ and $\mathrm{mAT}_{2}$ remodeling with aging could be done for cardiovascular diseases. In contrast, Doughan et al. (2008) demonstrated that Ang II does not exert any effect on isolated mitochondria. Moreover, it will be necessary to elucidate how Ang II gains access to the intracellular space, either by internalization or by local synthesis (Inagami, 2011). The relevance of this intracellular action of Ang II on mitochondrial ROS production remains to be studied.

\section{FINAL NOTES AND PERSPECTIVES}

The main objective of this review was to emphasize the participation of mitochondria in the signaling pathways of RAAS. As we have shown, almost all the effects of RAAS involve the production of ROS, and the main source of them appears to be mitochondria. In summary, we attempted to call attention to the central role of cardiomyocyte mitochondria as the sites where the cellular signaling mediated by ROS converge.

\section{REFERENCES}

Abadir, P. M., Foster, D. B., Crow, M., Cooke, C. A., Rucker, J. J., Jain, A., et al. (2011). Identification and characterization of a functional mitochondrial angiotensin system. Proc. Natl. Acad. Sci. U.S.A. 108, 14849-14854. doi: 10.1073/pnas.1101507108

Aiello, E. A., and De Giusti, V. C. (2012). Regulation of the cardiac sodium/bicarbonate cotransporter by angiotensin II: potential contribution to sodium and calcium overload. Curr. Cardiol. Rev. 9, 24-32. doi: 10.2174/1573403X11309010005

Aiello, E. A., Villa-Abrille, M. C., Dulce, R. A., Cingolani, $H$. E., and Perez, N. G. (2005). Endothelin-1 stimulates the $\mathrm{Na}^{+} / \mathrm{Ca}^{2+}$ exchanger reverse mode through intracellular $\mathrm{Na}^{+}\left(\mathrm{Na}^{+}{ }_{\mathrm{i}}\right)$ dependent and $\mathrm{Na}^{+}{ }_{\mathrm{i}}$-independent pathways. Hypertension 45, 288-293. doi: 10.1161/01.HYP. 0000152700.58940.b2

Andrukhiv, A., Costa, A. D., West, I. C., and Garlid, K. D. (2006). Opening mito KATP increases superoxide generation from complex I of the electron transport chain. Am. J. Physiol. Heart Circ. Physiol. 291, H2067-H2074. doi: 10.1152/ ajpheart.00272.2006 pp.H2067-74

Baetz, D., Haworth, R. S., Avkiran, M., and Feuvray, D. (2002). The ERK

Mitochondria have been mainly thought as the organelles that generate energy. However, in the last years, we have learned that mitochondria are much more than only an "ATP-plant production". They are involved in cellular ion homeostasis, oxidative stress and cell survival or death. The main role of mitochondria seems to be the supervisor of cell functions. Mitochondria are the main source of ROS and, more important, they can interact with others sources of ROS in order to amplify the signal. Moreover, ROS regulate calcium signaling, which can also act as second messenger and further stimulate ROS production, creating a cycle, capable of being regulated at many steps (Figure 2).

As commented above, in the past ROS were thought exclusively as deleterious molecules. However, recent studies show that they appear to be very important second messengers that mediate different intracellular pathways. What has changed? The molecules, the stimuli and the sources are the same. Perhaps, we should believe that we are just beginning to uncover how the cells can use harmful reactive species for their own benefit.

Finally, we would like to highlight that mitochondrial ROS signaling may be an attractive target for therapeutic drugs in order to suppress RAAS signals. However, due to the complexity of the mechanisms involved, this idea requires careful evaluation, since targeting the wrong site at the wrong moment could not only worsen the disease, but could also suppress important physiological signaling pathways.

(2011). Mineralocorticoid receptor activation is crucial in the signaling pathway leading to the Anrep effect. J. Physiol. 589, 6051-6061. doi: 10.1113/jphysiol.2011.218750

Caldiz, C. I., Garciarena, C. D., Dulce, R. A., Novaretto, L. P., Yeves, A. M., Ennis, I. L., et al. (2007). Mitochondrial reactive oxygen species activate the slow force response to stretch in feline myocardium. J. Physiol. 584, 895-905. doi: 10.1113/jphysiol.2007.141689

Camara, A. K., Lesnefsky, E. J., and Stowe, D. F. (2010). Potential therapeutic benefits of strategies directed to mitochondria. Antioxid. Redox Signal. 13, 279-347. doi: 10.1089/ars.2009.2788

Chai, W., and Danser, A. H. (2006). Why are mineralocorticoid receptor antagonists cardioprotective? Naunyn Schmiedebergs. Arch. Pharmacol. 374, 153-162. doi: 10.1007/s00210-006-0107-9

Chai, W., Garrelds, I. M., Arulmani, U., Schoemaker, R. G., Lamers, J. M., and Danser, A. H. (2005). Genomic and nongenomic effects of aldosterone in the rat heart: why is spironolactone cardioprotective? Br. J. Pharmacol. 145, 664-671. doi: 10.1038/sj.bjp.0706220

Choudhary, R., Baker, K. M., and Pan, J. (2008). All-trans retinoic acid prevents angiotensin II- and mechanical stretch-induced reactive oxygen species generation and cardiomyocyte apoptosis. J. Cell. Physiol. 215, 172-181. doi: $10.1002 /$ jcp. 21297

Cingolani, H. E., Ennis, I. L., Aiello, E. A., and Perez, N. G. (2011) Role of autocrine/paracrine mechanisms in response to myocardial strain. Pflugers Arch. 462, 29-38. doi: 10.1007/s00424-011-0930-9

Cingolani, H. E., Perez, N. G., Aiello, E. A., and De Hurtado, M. C. (2005). Intracellular signaling following myocardial stretch: an autocrine/paracrine loop. Regul. Pept. 128, 211-220. doi: 10.1016/j.regpep.2004.12.011

Cingolani, H. E., Perez, N. G., Aiello, E. A., Ennis, I. L., Garciarena, C. D., Villa-Abrille, M. C., et al. (2008). Early signals after stretch leading to cardiac hypertrophy. Key role of NHE-1. Front. Biosci. 13, 7096-7114. doi: 10.2741/3213

Cingolani, H. E., Perez, N. G., and Camilion De Hurtado, M. C. (2001). An autocrine/paracrine mechanism triggered by myocardial stretch induces changes in contractility. News Physiol. Sci. 16, 88-91.

Cingolani, H. E., Perez, N. G., Cingolani, O. H., and Ennis, I. L. (2013). The Anrep effect: 100 years later. Am. J. Physiol. Heart Circ. Physiol. 304, H175-H182. doi: 10.1152/ajpheart.00508.2012 
Cingolani, H. E., Perez, N. G., Pieske, B., Von Lewinski, D., and Camilion De Hurtado, M. C. (2003). Stretchelicited $\mathrm{Na}^{+} / \mathrm{H}^{+}$exchanger activation: the autocrine/paracrine loop and its mechanical counterpart. Cardiovasc. Res. 57, 953-960. doi: 10.1016/S0008-6363(02)00861-1

Cingolani, H. E., Villa-Abrille, M. C., Cornelli, M., Nolly, A., Ennis, I. L., Garciarena, C., et al. (2006). The positive inotropic effect of angiotensin II: role of endothelin-1 and reactive oxygen species. Hypertension 47, 727-734. doi: 10.1161/01.HYP. 0000208302.62399 .68

Costa, A. D., and Garlid, K. D. (2008). Intramitochondrial signaling: interactions among ${ }_{\text {mito }}$ KATP, PKCepsilon, ROS, and MPT. Am. J. Physiol. Heart Circ. Physiol. 295, H874-H882. doi: 10.1152/ajpheart.01189.2007

Costa, A. D., Jakob, R., Costa, C. L., Andrukhiv, K., West, I. C., and Garlid, K. D. (2006). The mechanism by which the mitochondrial ATP-sensitive $\mathrm{K}^{+}$channel opening and $\mathrm{H}_{2} \mathrm{O}_{2}$ inhibit the mitochondrial permeability transition. J. Biol. Chem. 281, 20801-20808. doi: 10.1074/jbc.M600959200

D'autreaux, B., and Toledano, M. B. (2007). ROS as signaling molecules: mechanisms that generate specificity in ROS homeostasis. Nat. Rev. Mol. Cell. Biol. 8, 813-824. doi: $10.1038 / \mathrm{nrm} 2256$

Dai, D. F., Johnson, S. C., Villarin, J. J., Chin, M. T., Nieves-Cintron, M., Chen, T., et al. (2011). Mitochondrial oxidative stress mediates angiotensin II-induced cardiac hypertrophy and Galphaq overexpression-induced heart failure. Circ. Res. 108, 837-846. doi: 10.1161/CIRCRESAHA.110. 232306

Daiber, A. (2010). Redox signaling (cross-talk) from and to mitochondria involves mitochondrial pores and reactive oxygen species. Biochim. Biophys. Acta 1797, 897-906. doi: 10.1016/j.bbabio.2010.01.032

De Giusti, V. C., Correa, M. V., Villa-Abrille, M. C., Beltrano, C., Yeves, A. M., De Cingolani, G. E., et al. (2008). The positive inotropic effect of endothelin-1 is mediated by mitochondrial reactive oxygen species. Life Sci. 83, 264-271. doi: 10.1016/j.lfs.2008.06.008

De Giusti, V. C., Garciarena, C. D., and Aiello, E. A. (2009). Role of reactive oxygen species (ROS) in angiotensin II-induced stimulation of the cardiac $\mathrm{Na}^{+} / \mathrm{HCO}_{3}{ }^{-}$cotransport.
J. Mol. Cell. Cardiol. 47, 716-722. doi: 10.1016/j.yjmcc.2009.07.023

De Giusti, V. C., Nolly, M. B., Yeves, A. M., Caldiz, C. I., Villa-Abrille, M. C., Chiappe De Cingolani, G. E., et al. (2011). Aldosterone stimulates the cardiac $\mathrm{Na}^{+} / \mathrm{H}^{+}$ exchanger via transactivation of the epidermal growth factor receptor. Hypertension 58, 912-919. doi: 10.1161/HYPERTEN SIONAHA.111.176024

Dedkova, E. N., Seidlmayer, L. K., and Blatter, L. A. (2013). Mitochondriamediated cardioprotection by trimetazidine in rabbit heart failure. J. Mol. Cell. Cardiol. 59C, 41-54. doi: 10.1016/j.yjmcc.2013.01.016

Diez, J. (2008). Effects of aldosterone on the heart: beyond systemic hemodynamics? Hypertension 52, 462-464. doi: 10.1161/HYPERTEN SIONAHA.108.117044

Dikalov, S. (2011). Cross talk between mitochondria and NADPH oxidases. Free Radic. Biol. Med. 51, 1289-1301. doi: 10.1016/j.freerad biomed.2011.06.033

Domenighetti, A. A., Boixel, C., Cefai, D., Abriel, H., and Pedrazzini, T. (2007). Chronic angiotensin II stimulation in the heart produces an acquired long QT syndrome associated with IK1 potassium current downregulation. J. Mol. Cell. Cardiol. 42, 63-70. doi: 10.1016/j.yjmcc.2006.09.019

Doughan, A. K., Harrison, D. G., and Dikalov, S. I. (2008). Molecular mechanisms of angiotensin II-mediated mitochondrial dysfunction: linking mitochondrial oxidative damage and vascular endothelial dysfunction. Circ. Res. 102, 488-496. doi: 10.1161/CIRCRESAHA.107.162800

Drose, S. (2013). Differential effects of complex II on mitochondrial ROS production and their relation to cardioprotective preand postconditioning. Biochim. Biophys. Acta 1827, 578-587. doi: 10.1016/j.bbabio.2013.01.004

Ebata, S., Muto, S., Okada, K., Nemoto, J., Amemiya, M., Saito, T., et al. (1999). Aldosterone activates $\mathrm{Na}^{+} / \mathrm{H}^{+}$exchange in vascular smooth muscle cells by nongenomic and genomic mechanisms. Kidney Int. 56, 1400-1412. doi: 10.1046/j.1523-1755.1999.00674.x

Ennis, I. L., Garciarena, C. D., Escudero, E. M., Perez, N. G., Dulce, R. A., Camilion De Hurtado, M. C., et al. (2007). Normalization of the calcineurin pathway underlies the regression of hypertensive hypertrophy induced by $\mathrm{Na}^{+} / \mathrm{H}^{+}$ exchanger-1 (NHE-1) inhibition.
Can. J. Physiol. Pharmacol. 85, 301-310. doi: 10.1139/Y06-072

Fischer, R., Dechend, R., Gapelyuk, A., Shagdarsuren, E., Gruner, K., Gruner, A., et al. (2007). Angiotensin II-induced sudden arrhythmic death and electrical remodeling. Am. J. Physiol. Heart Circ. Physiol. 293, H1242-H1253. doi: 10.1152/ajpheart.01400.2006

Fliegel, L., and Karmazyn, M. (2004). The cardiac $\mathrm{Na}-\mathrm{H}$ exchanger: a key downstream mediator for the cellular hypertrophic effects of paracrine, autocrine and hormonal factors. Biochem. Cell. Biol. 82, 626-635. doi: 10.1139/o04-129

Garciarena, C. D., Caldiz, C. I., Correa, M. V., Schinella, G. R., Mosca, S. M., Chiappe De Cingolani, G. E., et al. (2008). $\mathrm{Na}^{+} / \mathrm{H}^{+}$exchanger-1 inhibitors decrease myocardial superoxide production via direct mitochondrial action. J. Appl. Physiol. 105, 1706-1713. doi: 10.1152/japplphysiol.90616.2008

Giordano, F. J. (2005). Oxygen, oxidative stress, hypoxia, and heart failure. J. Clin. Invest. 115, 500-508. doi: 10.1172/JCI24408

Gomez-Sanchez, E. P., Ahmad, N., Romero, D. G., and GomezSanchez, C. E. (2004). Origin of aldosterone in the rat heart. Endocrinology 145, 4796-4802. doi: 10.1210/en.2004-0295

Gros, R., Ding, Q., Liu, B., Chorazyczewski, J., and Feldman, R. D. (2013). Aldosterone mediates its rapid effects in vascular endothelial cells through Gper/Gpr30 activation. Am. J. Physiol. Cell Physiol. 304, C532-C540. doi: 10.1152/ajpcell.00203.2012

Gros, R., Ding, Q., Sklar, L. A., Prossnitz, E. E., Arterburn, J. B., Chorazyczewski, J., et al. (2011). GPR30 expression is required for the mineralocorticoid receptorindependent rapid vascular effects of aldosterone. Hypertension 57, 442-451. doi: 10.1161/HYPERTEN SIONAHA.110.161653

Grossmann, C., and Gekle, M. (2007). Non-classical actions of the mineralocorticoid receptor: misuse of EGF receptors? Mol. Cell. Endocrinol. 277, 6-12. doi: 10.1016/j.mce.2007.07.001

Grossmann, C., and Gekle, M. (2009). New aspects of rapid aldosterone signaling. Mol. Cell Endocrinol. 308, 53-62. doi: 10.1016/j.mce.2009.02.005

Grossmann, C., Husse, B., Mildenberger, S., Schreier, B., Schuman, K., and Gekle, M. (2010). Colocalization of mineralocorticoid and EGF receptor at the plasma membrane. Biochim. Biophys. Acta 1803, 584-590. doi: 10.1016/j.bbamcr. 2010.02.008

Grossmann, C., Krug, A. W., Freudinger, R., Mildenberger, S., Voelker, K., and Gekle, M. (2007). Aldosterone-induced EGFR expression: interaction between the human mineralocorticoid receptor and the human EGFR promoter. Am. J. Physiol. Endocrinol. Metab. 292, E1790-E1800. doi: 10.1152/ajpendo.00708.2006

Gul, R., Shawl, A. I., Kim, S. H., and Kim, U. H. (2012). Cooperative interaction between reactive oxygen species and $\mathrm{Ca}^{2+}$ signals contributes to angiotensin II-induced hypertrophy in adult rat cardiomyocytes. Am. J. Physiol. Heart Circ. Physiol. 302, H901-H909. doi: 10.1152/ajpheart.00250.2011

Guo, P., Nishiyama, A., Rahman, M., Nagai, Y., Noma, T., Namba, T., et al. (2006). Contribution of reactive oxygen species to the pathogenesis of left ventricular failure in Dahl salt-sensitive hypertensive rats: effects of angiotensin II blockade. J. Hypertens. 24, 1097-1104. doi: 10.1097/01.hjh. $0000226200.73065 .5 \mathrm{~d}$

Hanna, I. R., Taniyama, Y., Szocs, K., Rocic, P., and Griendling, K. K. (2002). NAD(P)H oxidasederived reactive oxygen species as mediators of angiotensin II signaling. Antioxid. Redox. Signal. 4, 899-914. doi: 10.1089/ 152308602762197443

Hayashi, H., Kobara, M., Abe, M. Tanaka, N., Gouda, E., Toba, H., et al. (2008). Aldosterone nongenomically produces NADPH oxidase-dependent reactive oxygen species and induces myocyte apoptosis. Hypertens. Res. 31, 363-375. doi: 10.1291/hypres.31.363

Husain, A., Kinoshita, A., Sung, S. S., Urata, H., and Bumpus, F. M. (1994). "Human heart chymase," in The Cardiac Renin-Angiotensin System, ed G. D. E. Lindpaintner (Armonk, NY: Futura Publishing), 309-332.

Inagami, T. (2011). Mitochondrial angiotensin receptors and aging. Circ. Res. 109, 1323-1324. doi: 10.1161/RES.0b013e31823f05e0

Javadov, S., Choi, A., Rajapurohitam, V., Zeidan, A., Basnakian, A. G., and Karmazyn, M. (2008). NHE-1 inhibition-induced cardioprotection against ischaemia/reperfusion is associated with attenuation of the mitochondrial permeability transition. Cardiovasc. Res. 77, 416-424. doi: 10.1093/cvr/cvm039 
Karmazyn, M., Liu, Q., Gan, X. T., Brix, B. J., and Fliegel, L. (2003). Aldosterone increases NHE-1 expression and induces NHE-1-dependent hypertrophy in neonatal rat ventricular myocytes. Hypertension 42, 1171-1176. doi: 10.1161/01.HYP. 0000102863.23854.0B

Kimura, S., Zhang, G. X., Nishiyama, A., Shokoji, T., Yao, L., Fan, Y. Y., et al. (2005a). Mitochondriaderived reactive oxygen species and vascular MAP kinases: comparison of angiotensin II and diazoxide. Hypertension 45, 438-444. doi: 10.1161/01.HYP.0000 157169.27818.ae

Kimura, S., Zhang, G. X., Nishiyama, A., Shokoji, T., Yao, L., Fan, Y. Y., et al. (2005b). Role of $\mathrm{NAD}(\mathrm{P}) \mathrm{H}$ oxidase- and mitochondria-derived reactive oxygen species in cardioprotection of ischemic reperfusion injury by angiotensin II. Hypertension 45, 860-866. doi: 10.1161/01.HYP.0000 163462.98381.7f

Kindler, D. D., Thiffault, C., Solenski, N. J., Dennis, J., Kostecki, V., Jenkins, R., et al. (2003). Neurotoxic nitric oxide rapidly depolarizes and permeabilizes mitochondria by dynamically opening the mitochondrial transition pore. Mol. Cell. Neurosci. 23, 559-573.

Krieg, T., Landsberger, M., Alexeyev, M. F., Felix, S. B., Cohen, M. V., and Downey, J. M. (2003). Activation of Akt is essential for acetylcholine to trigger generation of oxygen free radicals. Cardiovasc. Res. 58, 196-202.

Krieg, T., Qin, Q., Mcintosh, E. C., Cohen, M. V., and Downey, J. M. (2002). ACh and adenosine activate PI3-kinase in rabbit hearts through transactivation of receptor tyrosine kinases. Am. J. Physiol. Heart Circ. Physiol. 283, H2322-H2330. doi: 10.1152/ajpheart.00474.2002

Krieg, T., Qin, Q., Philipp, S., Alexeyev, M. F., Cohen, M. V., and Downey, J. M. (2004). Acetylcholine and bradykinin trigger preconditioning in the heart through a pathway that includes Akt and NOS. Am. J. Physiol. Heart Circ. Physiol. 287, H2606-H2611. doi: 10.1152/ajpheart.00600.2004

Kubin, A. M., Skoumal, R., Tavi, P., Konyi, A., Perjes, A., Leskinen, H., et al. (2011). Role of reactive oxygen species in the regulation of cardiac contractility. J. Mol. Cell. Cardiol. 50, 884-893. doi: 10.1016/j.yjmcc.2011.02.005

Lemarie, C. A., Paradis, P., and Schiffrin, E. L. (2008). New insights on signaling cascades induced by cross-talk between angiotensin II and aldosterone. J. Mol. Med. (Berl.) 86, 673-678 doi: 10.1007/s00109-008-0323-5

Li, L., Zhang, Z. G., Lei, H., Wang, C., Wu, L. P., Wang, J. Y., et al. (2013). Angiotensin II reduces cardiac AdipoR1 expression through AT1 receptor/ROS/ERK1/2/c-Myc pathway. PLOS ONE 8:e49915. doi: 10.1371/journal.pone.0049915

Maulik, S. K., and Kumar, S. (2012). Oxidative stress and cardiac hypertrophy: a review. Toxicol. Mech. Methods 22, 359-366. doi: 10.3109/15376516.2012.666650

Mehta, P. K., and Griendling, K. K. (2007). Angiotensin II cell signaling: physiological and pathological effects in the cardiovascular system. Am. J. Physiol. Cell Physiol. 292, C82-C97. doi: 10.1152/ajpcell.00287.2006

Meyer, M. R., Prossnitz, E. R., and Barton, M. (2011). The G protein-coupled estrogen receptor GPER/GPR30 as a regulator of cardiovascular function. Vascul. Pharmacol. 55, 17-25. doi: 10.1016/j.vph.2011.06.003

Mihailidou, A. S., Mardini, M., and Funder, J. W. (2004). Rapid, nongenomic effects of aldosterone in the heart mediated by epsilon protein kinase C. Endocrinology 145, 773-780. doi: 10.1210/en.2003-1137

Miller, E. W., Dickinson, B. C., and Chang, C. J. (2010). Aquaporin3 mediates hydrogen peroxide uptake to regulate downstream intracellular signaling. Proc. Natl. Acad. Sci. U.S.A. 107, 15681-15686. doi: 10.1073/pnas. 1005776107

Morgan, P. E., Correa, M. V., Ennis, I. L., Diez, A. A., Perez, N. G., and Cingolani, H. E. (2011). Silencing of sodium/hydrogen exchanger in the heart by direct injection of naked siRNA. J. Appl. Physiol. 111, 566-572. doi: 10.1152/japplphysiol.00200.2011

Nishio, S., Teshima, Y., Takahashi, N., Thuc, L. C., Saito, S., Fukui, A., et al. (2012). Activation of CaMKII as a key regulator of reactive oxygen species production in diabetic rat heart. J. Mol. Cell Cardiol. 52, 1103-1111. doi: 10.1016/j.yjmcc.2012.02.006

Oldenburg, O., Qin, Q., Krieg, T., Yang, X. M., Philipp, S., Critz, S. D., et al. (2004). Bradykinin induces mitochondrial ROS generation via NO, cGMP, PKG, and mito KATP channel opening and leads to cardioprotection. Am. J. Physiol. Heart
Circ. Physiol. 286, H468-H476. doi: 10.1152/ajpheart.00360.2003

Pain, T., Yang, X. M., Critz, S. D., Yue, Y., Nakano, A., Liu, G. S., et al. (2000). Opening of mitochondrial $\mathrm{K}_{\mathrm{ATP}}$ channels triggers the preconditioned state by generating free radicals. Circ. Res. 87, 460-466. doi: 10.1161/01.RES.87.6.460

Palomeque, J., Delbridge, L., and Petroff, M. V. (2009). Angiotensin II: a regulator of cardiomyocyte function and survival. Front. Biosci. 14:5118-5133. doi: $10.2741 / 3590$

Perez, N. G., De Hurtado, M. C., and Cingolani, H. E. (2001). Reverse mode of the $\mathrm{Na}^{+}-\mathrm{Ca}^{2+}$ exchange after myocardial stretch: underlying mechanism of the slow force response. Circ. Res. 88, 376-382. doi: 10.1161/01.RES.88.4.376

Perez, N. G., Villa-Abrille, M. C., Aiello, E. A., Dulce, R. A., Cingolani, H. E., and Camilion De Hurtado, M. C. (2003). A low dose of angiotensin II increases inotropism through activation of reverse $\mathrm{Na}^{+} / \mathrm{Ca}^{2+}$ exchange by endothelin release. Cardiovasc. Res. 60, 589-597. doi: 10.1016/j.cardiores.2003.09.004

Qin, W., Rudolph, A. E., Bond, B. R., Rocha, R., Blomme, E. A., Goellner, J. J., et al. (2003). Transgenic model of aldosteronedriven cardiac hypertrophy and heart failure. Circ. Res. 93, 69-76. doi: 10.1161/01.RES.00000 80521.15238.E5

Rothstein, E. C., Byron, K. L., Reed, R. E., Fliegel, L., and Lucchesi, P. A. (2002). $\mathrm{H}_{2} \mathrm{O}_{2}$-induced $\mathrm{Ca}^{2+}$ overload in NRVM involves ERK1/2 MAP kinases: role for an NHE-1-dependent pathway. Am. J. Physiol. Heart Circ. Physiol. 283, H598-H605. doi: 10.1152/ajpheart.00198.2002

Sabri, A., Byron, K. L., Samarel, A. M., Bell, J., and Lucchesi, P. A. (1998). Hydrogen peroxide activates mitogen-activated protein kinases and $\mathrm{Na}^{+}-\mathrm{H}^{+}$exchange in neonatal rat cardiac myocytes. Circ. Res. 82, 1053-1062. doi 10.1161/01.RES.82.10.1053

Sadoshima, J., and Izumo, S. (1996). Autocrine secretion of angiotensin II mediates stretch-induced hypertrophy of cardiac myocytes in vitro. Contrib. Nephrol. 118, 214-221. doi 10.1016/0092-8674(93)90541-W

Sadoshima, J., Xu, Y., Slayter, H. S., and Izumo, S. (1993). Autocrine release of angiotensin II mediates stretch-induced hypertrophy of cardiac myocytes in vitro. Cell 75 , 977-984.

Sato, T., O'rourke, B., and Marban, E. (1998). Modulation of mitochondrial ATP-dependent $\mathrm{K}+$ channels by protein kinase C. Circ. Res. 83, 110-114. doi: 10.1161/01.RES.83.1.110

Seshiah, P. N., Weber, D. S., Rocic, P., Valppu, L., Taniyama, Y., and Griendling, K. K. (2002). Angiotensin II stimulation of $\mathrm{NAD}(\mathrm{P}) \mathrm{H}$ oxidase activity: upstream mediators. Circ. Res. 91, 406-413. doi: 10.1161/01.RES. 0000033523.08033 .16

Shah, B. H., and Catt, K. J. (2003). A central role of EGF receptor transactivation in angiotensin II -induced cardiac hypertrophy. Trends Pharmacol. Sci. 24, 239-244. doi: 10.1016/S0165-6147(03)00079-8

Silvestre, J. S., Heymes, C., Oubenaissa, A., Robert, V., Aupetit-Faisant, B., Carayon, A., et al. (1999). Activation of cardiac aldosterone production in rat myocardial infarction: effect of angiotensin II receptor blockade and role in cardiac fibrosis. Circulation 99, 2694-2701. doi: 10.1161/01.CIR.99.20.2694

Silvestre, J. S., Robert, V., Heymes, C., Aupetit-Faisant, B., Mouas, C., Moalic, J. M., et al. (1998). Myocardial production of aldosterone and corticosterone in the rat. Physiological regulation. J. Biol. Chem. 273, 4883-4891. doi: 10.1074/jbc.273.9.4883

Smaili, S. S., and Russell, J. T. (1999). Permeability transition pore regulates both mitochondrial membrane potential and agonist-evoked $\mathrm{Ca}^{2+}$ signals in oligodendrocyte progenitors. Cell. Calcium 26, 121-130. doi: 10.1054/ceca.1999.0061

Snabaitis, A. K., Hearse, D. J., and Avkiran, M. (2002). Regulation of sarcolemmal $\mathrm{Na}^{+} / \mathrm{H}^{+}$exchange by hydrogen peroxide in adult rat ventricular myocytes. Cardiovasc. Res. 53, 470-480.

Song, Y. H., Choi, E., Park, S. H., Lee, S. H., Cho, H., Ho, W. K., et al. (2011). Sustained CaMKII activity mediates transient oxidative stressinduced long-term facilitation of L-type $\mathrm{Ca}^{2+}$ current in cardiomyocytes. Free Radic. Biol. Med. 51, 1708-1716. doi: 10.1016/j.freerad biomed.2011.07.022

Sorescu, D., and Griendling, K. K. (2002). Reactive oxygen species, mitochondria, and $\mathrm{NAD}(\mathrm{P}) \mathrm{H}$ oxidases in the development and progression of heart failure. Congest. Heart Fail. 8, 132-140. doi: 10.1111/j.1527-5299.2002.00717.x

Szokodi, I., Kerkela, R., Kubin, A. M., Sarman, B., Pikkarainen, S., Konyi, A., et al. (2008). Functionally opposing roles of extracellular signal-regulated kinase $1 / 2$ and 
p38 mitogen-activated protein kinase in the regulation of cardiac contractility. Circulation 118, 1651-1658. doi: 10.1161/CIRCU LATIONAHA.107.758623

Takeda, Y., Yoneda, T., Demura, M., Miyamori, I., and Mabuchi, H. (2000). Cardiac aldosterone production in genetically hypertensive rats. Hypertension 36, 495-500. doi: 10.1161/01.HYP.36.4.495

Terentyev, D., Gyorke, I., Belevych, A. E., Terentyeva, R., Sridhar, A., Nishijima, Y., et al. (2008). Redox modification of ryanodine receptors contributes to sarcoplasmic reticulum $\mathrm{Ca}^{2+}$ leak in chronic heart failure. Circ. Res. 103, 1466-1472. doi: 10.1161/CIRCRESAHA.108.184457

Toda, T., Kadono, T., Hoshiai, M., Eguchi, Y., Nakazawa, S., Nakazawa, H., et al. (2007). $\mathrm{Na}^{+} / \mathrm{H}^{+}$exchanger inhibitor cariporide attenuates the mitochondrial $\mathrm{Ca}^{2+}$ overload and PTP opening. Am. J. Physiol. Heart Circ. Physiol. 293, H3517-H3523. doi: 10.1152/ ajpheart.00483.2006

Trebak, M., Ginnan, R., Singer, H. A., and Jourd'heuil, D. (2010). Interplay between calcium and reactive oxygen/nitrogen species: an essential paradigm for vascular smooth muscle signaling. Antioxid. Redox. Signal 12, 657-674. doi: 10.1089/ars.2009.2842

Varagic, J., and Frohlich, E. D. (2002). Local cardiac reninangiotensin system: hypertension and cardiac failure. J. Mol. Cell Cardiol. 34, 1435-1442. doi: 10.1006/jmcc.2002.2075

Vaughan-Jones, R. D., Villafuerte, F. C., Swietach, P., Yamamoto, T., Rossini, A., and Spitzer, K. W. (2006). pH-Regulated $\mathrm{Na}^{+}$ influx into the mammalian ventricular myocyte: the relative role of $\mathrm{Na}^{+}-\mathrm{H}^{+}$exchange and $\mathrm{Na}^{+}$-HCO Co-transport. J. Cardiovasc. Electrophysiol. 17(Suppl. 1), S134-S140. doi: 10.1111/j.1540-8167.2006.00394.x

Villa-Abrille, M. C., Caldiz, C. I., Ennis, I. L., Nolly, M. B., Casarini, M. J., Chiappe De Cingolani, G. E., et al. (2010). The Anrep effect requires transactivation of the epidermal growth factor receptor. J. Physiol. 588, 1579-1590. doi: 10.1113/jphysiol.2009.186619.

Villa-Abrille, M. C., Cingolani, H. E., Garciarena, C. D., Ennis, I. L., and Aiello, E. A. (2006). [Angiotensin IIinduced endothelin-1 release in cardiac myocytes]. Medicina (B Aires) 66, 229-236.

Wang, Y. H., Shi, C. X., Dong, F., Sheng, J. W., and Xu, Y. F. (2008). Inhibition of the rapid component of the delayed rectifier potassium current in ventricular myocytes by angiotensin II via the AT1 receptor. Br. J. Pharmacol. 154, 429-439. doi: 10.1038/bjp.2008.95

Wenzel, P., Mollnau, H., Oelze, M., Schulz, E., Wickramanayake, J. M., Muller, J., et al. (2008). First evidence for a crosstalk between mitochondrial and NADPH oxidase-derived reactive oxygen species in nitroglycerin-triggered vascular dysfunction. Antioxid. Redox. Signal. 10, 1435-1447. doi: 10.1089/ars.2007.1969

Wojtovich, A. P., Smith, C. O., Haynes, C. M., Nehrke, K. W., and Brookes, P. S. (2013). Physiological consequences of complex II inhibition for aging, disease, and the $\mathrm{mK}_{\text {ATP }}$ channel. Biochim. Biophys. Acta 1827 (5), 598-611. doi: 10.1016/j.bbabio.2012.12.007

Xiao, F., Puddefoot, J. R., Barker, S., and Vinson, G. P. (2004).
Mechanism for aldosterone potentiation of angiotensin II-stimulated rat arterial smooth muscle cell proliferation. Hypertension 44, 340-345. doi: 10.1161/01.HYP. 0000140771.21243.ed

Yoshida, K., Kim-Mitsuyama, S., Wake, R., Izumiya, Y., Izumi, Y., Yukimura, T., et al. (2005). Excess aldosterone under normal salt diet induces cardiac hypertrophy and infiltration via oxidative stress. Hypertens. Res. 28, 447-455. doi: 10.1291/hypres.28.447

Zeng, Q., Zhou, Q., Yao, F., O'rourke, S. T., and Sun, C. (2008). Endothelin1 regulates cardiac L-type calcium channels via $\mathrm{NAD}(\mathrm{P}) \mathrm{H}$ oxidasederived superoxide. J. Pharmacol. Exp. Ther. 326, 732-738. doi: 10.1124/jpet.108.140301

Zhai, P., Galeotti, J., Liu, J., Holle, E., Yu, X., Wagner, T., et al. (2006). An angiotensin II type 1 receptor mutant lacking epidermal growth factor receptor transactivation does not induce angiotensin IImediated cardiac hypertrophy. Circ. Res. 99, 528-536. doi: 10.1161/01. RES.0000240147.49390.61

Zhang, D. X., Chen, Y. F., Campbell, W. B., Zou, A. P., Gross, G. J., and Li, P. L. (2001). Characteristics and superoxide-induced activation of reconstituted myocardial mitochondrial ATP-sensitive potassium channels. Circ. Res. 89, 1177-1183. doi: 10.1161/hh2401.101752

Zhang, G. X., Lu, X. M., Kimura, S., and Nishiyama, A. (2007). Role of mitochondria in angiotensin II-induced reactive oxygen species and mitogenactivated protein kinase activation. Cardiovasc. Res. 76, 204-212. doi: 10.1016/j.cardiores.2007.07.014

Zhao, Z., Fefelova, N., Shanmugam, M., Bishara, P., Babu, G. J., and
Xie, L. H. (2011). Angiotensin II induces afterdepolarizations via reactive oxygen species and calmodulin kinase II signaling. J. Mol. Cell Cardiol. 50, 128-136. doi: 10.1016/j.yjmcc.2010.11.001

Zorov, D. B., Filburn, C. R., Klotz, L. O., Zweier, J. L., and Sollott, S. J. (2000). Reactive oxygen species (ROS)-induced ROS release: a new phenomenon accompanying induction of the mitochondrial permeability transition in cardiac myocytes. J. Exp. Med. 192, 1001-1014. doi: 10.1084/jem.192.7.1001

Conflict of Interest Statement: The authors declare that the research was conducted in the absence of any commercial or financial relationships that could be construed as a potential conflict of interest.

Received: 25 January 2013; accepted: 13 May 2013; published online: 30 May 2013.

Citation: De Giusti VC, Caldiz CI, Ennis IL, Pérez NG, Cingolani HE and Aiello EA (2013) Mitochondrial reactive oxygen species (ROS) as signaling molecules of intracellular pathways triggered by the cardiac renin-angiotensin II-aldosterone system (RAAS). Front. Physiol. 4:126. doi: 10.3389/fphys.2013.00126

This article was submitted to Frontiers in Mitochondrial Research, a specialty of Frontiers in Physiology.

Copyright (C) 2013 De Giusti, Caldiz, Ennis, Pérez, Cingolani and Aiello. This is an open-access article distributed under the terms of the Creative Commons Attribution License, which permits use, distribution and reproduction in other forums, provided the original authors and source are credited and subject to any copyright notices concerning any third-party graphics etc. 